\title{
Cerebral germinoma revealed through a polydipsic polyuric syndrome in a 10 -year-old girl: case report
}

\author{
${ }^{1}$ Van Lierde L, ${ }^{2}$ Clapuyt P, ${ }^{1}$ Nassogne MC, ${ }^{3}$ Oriot P \\ ${ }^{1}$ Universite Catholique de Louvain, Cliniques Universitaires Saint-Luc, Brussels, Belgium; \\ ${ }^{2}$ Department of Radiology, Universite Catholique de Louvain, Saint-Luc, Brussels, Belgium; \\ ${ }^{3}$ Department of Endocrinology, Mouscron Hospital Centre, Mouscron, Belgium \\ E-mail:p.oriot@chmouscron.be
}

\begin{abstract}
Cerebral germinoma is rare. Although the imaging of the germinoma is very evocative, it's very polymorphic clinical expression is at the origin of misguided diagnosis, as illustrated in our case. We report the case of a 10-year-old girl with diabetes insipidus evolving for 12 months associated with a decrease in visual acuity. Brain MRI (Magnetic Resonance Imaging) revealed a tumor process in the suprasellar region. The stereotaxic biopsy of the tumor confirmed the diagnosis of the hypothalamic germinoma, which allowed the patient to be treated by radiotherapy and chemotherapy. The incidence of cerebral germinoma, its clinical (principally diabetes insipidus) and radiological features as well as therapeutic strategies are discussed hereby.
\end{abstract}

Key words: diabetes insipidus, panhypopituitarism, intracerebral germinoma

The cerebral germinomas are germ-line tumors representing $4 \%$ of childhood brain tumors (Resetkova et al. 2013). We report a new observation of cerebral germinoma discovered through a polyuric polydipsic syndrome. The literature has been reviewed with discussion of the diagnosis, the radiological criteria, and the treatment of these tumors.

\section{Subject and Results}

A 10 -year-old girl was hospitalized in the pediatric neurology unit for drowsiness and cognitive disorders. She also complained of frontal headaches and progressive polyuric polydipsic syndrome (drinking between 3 and 7 liters per day), associated with growth failure. Medical history was unremarkable, except for a deficit in Von Willebrandt factor detected during the pre-operative exams for adenoids. The clinical examination was normal; no sign of puberty was observed. A blood sample analysis showed a low free T4
(fT4) level at $7.4 \mathrm{pmol} / \mathrm{l}$ (reference $10.4-24.0 \mathrm{pmol} / \mathrm{l}$ ) with normal thyroid stimulating hormone (TSH) at $3.7 \mathrm{mU} / \mathrm{l}$ (reference $0.70-5.3 \mathrm{mU} / \mathrm{l}$ ), increased level of prolactin at $63.3 \mu \mathrm{g} / \mathrm{l}$ (reference $5.0-23.0 \mu \mathrm{g} / \mathrm{l}$ ), and low levels of gonadotropins. Plasma sodium and glucose were within the normal range. Therefore, central hypothyroidism and diabetes insipidus (DI) were suspected. Urine osmolality was low at $88 \mathrm{mOsm} / \mathrm{kg}$ (reference 300-900 $\mathrm{mOsm} / \mathrm{kg}$ ), while plasma osmolality was normal at $281 \mathrm{mOsm} / \mathrm{kg}$. A hydric deprivation test was not performed because the polyuric polydypsic syndrome was severe (3 to 7 liters per day). The concentration of anti-diuretic hormone $(\mathrm{ADH})$ was low $<0.5 \mathrm{pg} / \mathrm{ml}$ (reference $0.5-14 \mathrm{pg} / \mathrm{ml}$ ) confirming the DI. A glucagon test was performed (Table 1) to explore the anterior pituitary, there was no significant increase of plasma cortisol and growth hormone (GH) levels after stimulation. The deficit in fT4 and cortisol were treated by L-Thyroxine ${ }^{\varpi} 50 \mathrm{\mu g}$ /day and hydrocortisone, while DI was successfully treated by Minirin . 
Table 1

Glucagon test

\begin{tabular}{lcccccccc}
\hline Time $(\mathbf{m i n})$ & $\mathbf{- 1 5}$ & $\mathbf{0}$ & $\mathbf{3 0}$ & $\mathbf{6 0}$ & $\mathbf{9 0}$ & $\mathbf{1 2 0}$ & $\mathbf{1 5 0}$ & $\mathbf{1 8 0}$ \\
\hline Glucose $(\mathrm{mg} / \mathrm{dl})$ & 61 & 66 & 216 & 240 & 186 & 101 & 65 & 48 \\
GH $(\mathrm{ng} / \mathrm{ml})$ & - & 0.17 & 0.13 & 1.17 & 1.15 & 0.66 & 0.23 & 0.13 \\
Cortisol $(\mathrm{nmol} / \mathrm{l})$ & 91.7 & 111.3 & 102.6 & 89.5 & 124.3 & 166.8 & 138.8 & 128.3 \\
\hline
\end{tabular}

Normal response: peak of GH $>5 \mathrm{ng} / \mathrm{ml}$; Partial insufficiency: GH between $3-5 \mathrm{ng} / \mathrm{ml}$; Insufficiency: GH $<3$ ng/ml; Insufficiency: Cortisol $<550 \mathrm{nmol} / \mathrm{l}$.

To confirm the central origin of the hormonal deficit, brain MRI was performed and showed a major hypothalamic mass developed above the hypothalamus, enhancing intensely after contrast and compressing the optic chiasm. There was no associated hydrocephalus. The medullary MRI was normal, without evidence of other tumor localizations. The ophthalmologic exam showed low visual acuity due to the optic nerves compression. The visual field test was disrupted to the right eye and showed a left lateral hemianopia to the left eye.

Plasma levels of the alpha1-foetoprotein were measured at $8.3 \mu \mathrm{g} / \mathrm{l}$ (reference $<9.0 \mu \mathrm{g} / \mathrm{l}$ ) and of $\beta$-human chorionic gonadotropin ( $\beta$-HCG) at $<0.16 \mathrm{mUI} / \mathrm{ml}$ (reference $<0.16 \mathrm{mUI} / \mathrm{ml}$ ). The lumbar puncture showed similar low marker concentrations and no malignant cells. Positron emission tomography- methionine computed tomography (PET-methionine $\mathrm{CT}$ ) revealed a hypermetabolic core inside the tumor. A biopsy was finally performed through neuronavigation (Figure 1). The cytological analysis showed increased nuclei size, irregular contour, and hyperchromatic. These cells were dissociated by rela- tively large vascular structures with a focal pseudoepithelial palissadic disposition. Focal glandular epithelial differentiation was also focalized. No necrosis range was formally objectified. Immunologically, the tumor cells express antigen CD117, weakly alpha1foetoprotein, and none $\beta$-HCG. On the other hand, there was a persistence of the nuclear immunostaining of neoplastic cells by BAF47/INI1. The MRI, histological, and immunohistochemical examinations confirmed a germ cell tumor, rather type germinoma with focal epithelial differentiation even beginner embryonal carcinoma. In order to preserve the patient's fertility, ovarian tissue cryopreservation was performed, the patient was consequently treated by chemotherapy and radiotherapy (Resetkova et al. 2013).

\section{Discussion and conclusion}

Germ cell tumors contribute to $4 \%$ of childhood brain tumors, with an incidence peaking around puberty. They occur mostly in the testes (25\%), ovaries $(25 \%)$, sacrococcygeal region $(20 \%)$, and the central nervous system (20\%) (Calaminus et al. 2013). The

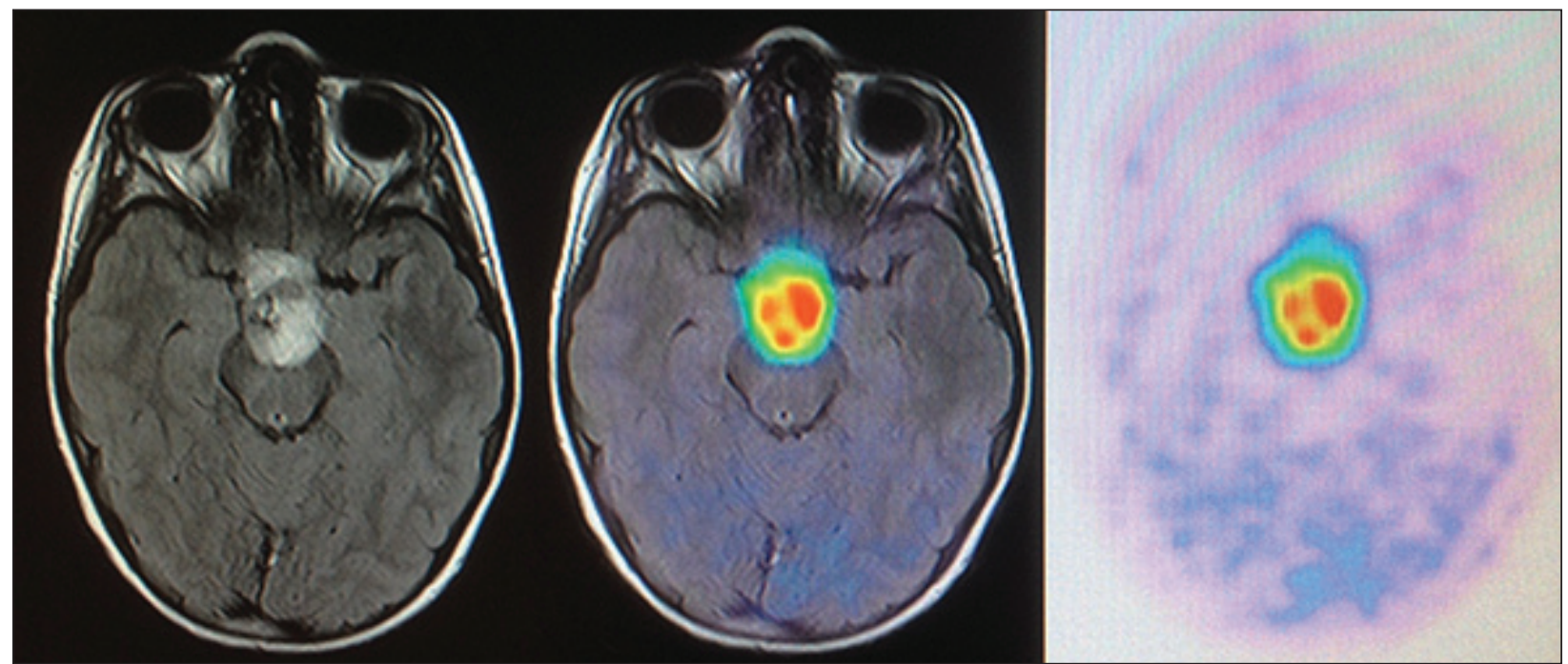

Figure 1. PET Methionine-CT revealed a hypermetabolic core inside the hypothalamic mass developed above the hypothalamus. 
germ cell tumors of the central nervous system are rare and usually arise from the midline structures (Hayashi et al. 2009). It has been hypothesized that the pathogenesis is a result of the aberrant migration of the primordial germ cells from the midline embryonic disk. Their most common sites of occurrence include the pineal gland and the supra or neurohypophyseal regions, some tumors being bifocal (Kishore et al. 2014). the intracranial germ cell tumors are further divided into 6 histologic subtypes: germinoma, teratoma, embryonal carcinoma, choriocarcinoma, yolk sac tumor, and mixed tumor (Louis et al. 2007). The germinomas account for 50 to $66 \%$ of all the intracranial germ cell tumors.

The clinical expression of the germinomas is polymorphic. They are most often revealed by DI, as shown in our observation. The young patient presented with an ongoing polyuric polydipsic syndrome at first (since several months) and in the absence of other symptoms, the behavior was regarded as a probable mental disorder, like potamania, especially since her parents were divorcing. Although the etiologic diagnosis of polyuric polydipsic syndrome can be misleading, there are some differences between symptoms of DI and potomania. DI appears suddenly, even overnight, and is principally accompanied by loss of considerable volumes of urine, as opposed to potomania, which does not occur suddenly and does not present with nycturia. However, the water deprivation test can be very helpful to differentiate between potomania and DI (Metropulos and Antoon 2015). In our case, the water deprivation test was not available, as the patient's drinking needs were too important to perform it. Another method

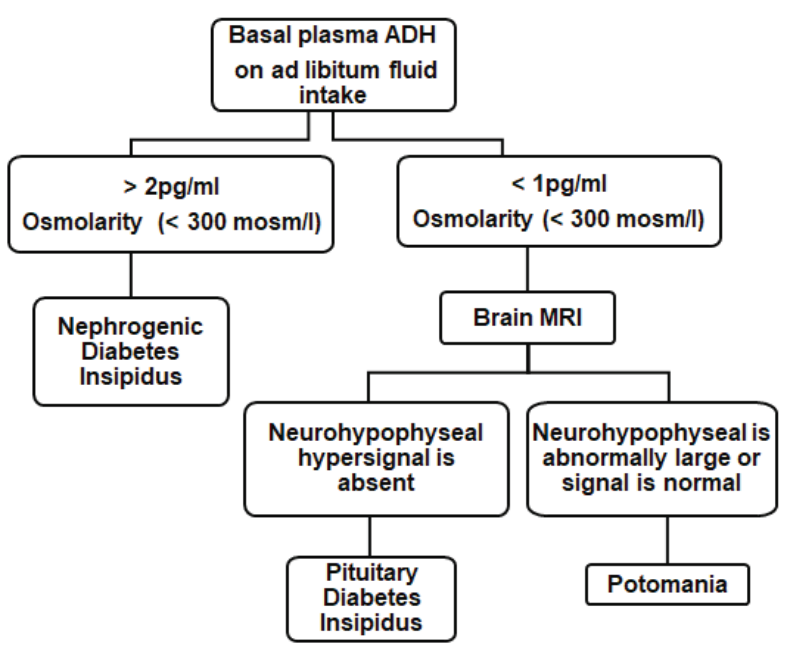

Figure 2. ADH-MRI method. (Robertson 2016). to replace this test is the ADH-MRI-method (Robertson 2016). It is based on two observations. The first one implies that basal plasma $\mathrm{ADH}$ levels are always low or undetectable in potomania and pituitary diabetes insipidus, though they are normal or elevated in nephrogenic DI. The second observation involves an MRI. The neurohypophysis appears with a high signal in T1. This signal is present or enlarged in potomania, but absent or abnormally small in the pituitary DI. Therefore, these three types of polydipsia can be differentiated following two steps, like described by Robertson (2016) (Figure 2). First, a measure of basal plasma ADH and urine osmolarity (in unrestricted fluid intake conditions). If plasma $\mathrm{ADH}$ is normal or elevated $>2.0 \mathrm{pg} / \mathrm{ml}$, while urine osmolarity is low $(<300 \mathrm{mosm} / \mathrm{l})$, the patient suffers from nephrogenic DI. If plasma ADH is low or undetectable $<1 \mathrm{pg} / \mathrm{ml}$ when urine osmolarity is also low, the brain MRI is needed. It can determine whether the neurohypophyseal hypersignal is absent, indicating pituitary DI, or normal or abnormally large, indicating potomania. MRI can help to identify signs of the pathology causing the disorder. In this clinical presentation, the germinoma appear as an isointense T1, hyperintense T2 mass with marked gadolinium enhancement (Robertson 2016).

Supracellar germinoma can also be manifested by lead to anterior pituitary deficiencies in more than $50 \%$ of patients. Moderate hyperprolactinemia is present in most cases (30 to $60 \mathrm{ng} / \mathrm{ml}$ ), which suggest hypothalamic lesions caused by brain tumors (e.g. craniopharyngiomas) or hypothalamic-pituitary infiltrations (such as sarcoidosis or histiocytosis $\mathrm{X}$ ) are responsible for hyperprolactinemia due to loss of dopamine inhibition on secretion of pituitary prolactin (Teinturier and Bougneres 2002). As illustrated by our observation, the young girl presented low levels of TSH, GH, cortisol, and ADH, which can be explained by a compression of the infundibulum, stalk and/or pituitary gland by the tumor. Regarding the differential diagnosis, some authors have described pubertal delay due to the hypogonadism and hyperprolactinemia (Echevarria et al. 2008). However, the tumor can also lead to an early onset of puberty (before 8 years for girls). The precocious puberty can arise in 5\% of patients in pineal and/or hypothalamic tumors. $\beta$-HCG and luteinizing hormone (LH) levels may be elevated in some patients with precocious puberty, and choriocarcinomas are more likely to be present with precocious puberty than any other type of germ cell tumors. Finally, visual disturbances linked intracranial hypertension are often described (Hoffman et al. 1991). 
The presence of specific protein markers ( $\beta$-HCG and alfa-fetoprotein) that can be secreted by some tumors may be an important tool in the diagnosis of the germ cell tumors. At high levels, these protein markers can be measured in the serum, although cerebrospinal fluid levels are more sensitive and reliable parameters. Low levels of $\beta$-HCG have been detected in a variety of tumors. It may be a non-specific marker of malignancy. A mild elevation of $\beta$-HCG has been noted in the syncytiotrophoblastic form of the germinoma (Echevarria et al. 2008). Increased alfafetoprotein levels may indicate the presence of cancer, most commonly liver cancer, cancer of the ovary, or the germ cell tumor. However, not every cancer will produce significant quantities of alfa-fetoprotein. The definitive diagnosis of an intracranial germ cell tumor usually requires histological confirmation. In our case, a biopsy of the mass was required to confirm the diagnostic because the tumor markers were not elevated (National Cancer Institute 2015).

The treatment of this tumor is based on the International Society of Peadiatric Oncologic (SIOP) CNS GCT II-non-metastatic protocol. This proto- col includes primary chemotherapy consisting of Carboplatin and Etoposide, alternated with Ifosfamide and Etoposide. Radiotherapy should follow chemotherapy, or surgical resection of a residual mass has to be performed as soon as possible, if it is necessary. The radiotherapy will consist of entire ventricular irradiation, ensuring that the original area of the tumor is included (Kim and Park 2015). The treatment success rate for germinomas depends more on the radiation volume, which should cover the entire ventricular space than the radiation dose itself. Neoadjuvant chemotherapy is given to reduce the size of the tumor in order to lower the radiation dose. These therapies have the merit of the decreasing long term neurological consequences of radiotherapy. The prognosis for patients with germinomas is quite good, with many reports indicating the survival rate being greater than $90 \%$ five years following the diagnosis and treatment. The young girl patient had her third course of chemotherapy following the SIOP CNS GCT II-protocol in the context of a nonsecreting cerebral germinoma. Chemotherapy was very well tolerated.

\section{References}

Calaminus G, Kortmann R, Worch J, Nicholson JC, Alapetite C, Garre ML, Patte C, Ricardi U, Saran F, Frappaz D. SIOP CNS GCT 96: final report of outcome of a prospective, multinational nonrandomized trial for children and adults with intracranial germinoma, comparing craniospinal irradiation alone with chemotherapy followed by focal primary site irradiation for patients with localized disease. Neuro Oncol 15, 788-796, 2013.

Echevarria ME, Fangusaro J, Goldman S. Pediatric central nervous system germ cell tumors: a review. Oncologist 13, 690-699, 2008.

Hayashi Y, Watanabe T, Nakada M, Kita D, Hayashi Y, Uchiyama N, Hamada J. BCL10 single nucleotide polymorphism and its association with CSF dissemination of primary intracranial germ cell tumors. Pediatr Neurosurg 45, 291-295, 2009.

Hoffman HJ, Otsubo H, Hendrick EB, Humphreys RP, Drake JM, Becker LE, Greenberg M, Jenkin D. Intracranial germ-cell tumors in children. J Neurosurg 74, 545-551, 1991.

Kim JY, Park J. Understanding the treatment strategies of intracranial germ cell tumors: Focusing on radiotherapy. J Korean Neurosurg Soc 57, 315-322, 2015.

Kishore M, Monappa V, Rao L, Kudva R. Mixed malignant germ cell tumour of third ventricle with hydrocephalus: a rare case with recurrence. J Clin Diagn Res 8, FD03-FD05, 2014.

Louis DN, Ohgaki H, Wiestler OD, Cavenee WK, Burger PC, Jouvet A, Scheithauer BW, Kleihues P. The 2007 WHO classification of tumours of the central nervous system. Acta Neuropathol 114, 97-109, 2007.

Metropulos D, Antoon JW. Primary polydipsia in a child. Clin Pediatr (Phila) 54, 1396-1398, 2015.

National Cancer Institute (2015). Childhood central nervous system germ cell tumors. On line http://www.cancer. gov/types/brain/hp/child-cns-germ-cell-treatment-pdq\#cit/, consulted July 20, 2016.

Resetkova N, Hayashi M, Kolp LA, Christianson MS. Fertility preservation for prepubertal girls: Update and current challenges. Curr Obstet Gynecol Rep 2, 218-225, 2013.

Robertson GL. Diabetes insipidus: Differential diagnosis and management. Best Pract Res Clin Endocrinol Metab 30, 205-218, 2016.

Teinturier C, Bougneres PF. Germinome de la tige pituitaire: diagnostic et indications therapeutiques. Medecine Therapeutique Endocrinologie \& Reproduction 3, 424-429, 2002. 